\title{
A Modified Cylinder Block-IC Engine Experimentation
}

\author{
Mohd Abdul Samad, Syed Nawazish Mehdi, Syed Khader basha
}

\begin{abstract}
In Internal combustion Engines, the adequate cooling plays vital role for proper functioning and enhanced efficiencies. In the present scenario, the demand for Air cooled Engines with higher powers is increasing and hence necessity for Augmented heat transfer through fins. The present work confined to fins mounted on the cylinder block.In the present work, Internal Combustion Engine test rig is used, which consist of $4 S$, single cylinder, vertical, air cooled, SI Engine with Instrumentation panel, Throttle control mechanism and Electrical Loading system. The performance test on IC engine is carried out for three various configurations of cylinder blocks i.e., 1. Actual cylinder block 2.Cylinder block with triangular profile fins 3. Cylinder block with perforated triangular profile fins. Performance parameters are evaluated, plotted and compared \& eventually conclusions are made.
\end{abstract}

Keywords: Cylinder Block with Perforated Triangular Profile Fins.

\section{INTRODUCTION}

Engines are broadly classified into internal combustion engines and external combustion engines. In internal combustion engines, combustion takes place inside the cylinder. During combustion hot gases are produced at temperature of about $2500^{\circ} \mathrm{C}$. Consequently heat is absorbed by cylinder walls, piston, cylinder head and valves and further, temperature of these parts increases. Subsequently leads to malfunctioning of the engine. Hence this necessitates the proper cooling system. Cooling system can be either water cooled or air cooled. Due to light weight and other advantages, air cooled engines are mostly used for automobile applications.

\section{ENGINE SPECIFICATION}

TABLE 1: IC ENGINE SPECIFICATION

\begin{tabular}{|l|l|}
\hline Number of Cylinders & One (1) \\
\hline Bore Dia & $57.30 \mathrm{~mm}$ \\
\hline Stroke Dia & $57.80 \mathrm{~mm}$ \\
\hline Displacement of Piston & $149.2 \mathrm{Sq} . \mathrm{cm}$ \\
\hline
\end{tabular}

Manuscript received on December 19, 2020.

Revised Manuscript received on December 31, 2020.

Manuscript published on February 28, 2021.

*Corresponding Author

Mohd Abdul Samad*, Assistant Professor, Department of Mechanical Engineering, MJCET, Hyderabad, India. Email: masamad@mjcollege.ac.in

Dr. Syed Nawazish Mehdi, Research Supervisor, Department of Mechanical Engineering, Mewar University, Rajasthan, India. Email: nawazishmehdi@yahoo.co.in

Dr. Syed Khader Basha, Assistant Professor, Department of Mechanical Engineering, MJCET, Hyderabad, India. Email: khader.basha@mjcollege.ac.in

(C) The Authors. Published by Blue Eyes Intelligence Engineering and Sciences Publication (BEIESP). This is an open access article under the CC BY-NC-ND license (http://creativecommons.org/licenses/by-nc-nd/4.0/)

\begin{tabular}{|l|l|}
\hline C.R (Compression Ratio) & $9.1: 1.0$ \\
\hline Fuel & Petrol \\
\hline Position of the Engine & Vertical \\
\hline
\end{tabular}

\section{EXPERIMENTAL APPARATUS AND METHODS}

Experimentation is being carried out with internal combustion Engine test rig which consists of following components

1. I.C Engine

2. Instrumentation panel, which consist of burette, manometer, rpm indicator and energy meter.

3. Throttle control mechanism

4. Anemometer

5. A.C Generator with electrical load bank.

once the test rig is being prepared, internal combustion engine is started with self stator with the help of battery.

The below mentioned parameters are noted after observation for different wind speeds at constant speeds of the I.C engine

1. Fuel consumed in the burette

2. Water level difference in manometer

3. Speed of the engine

4. Energy meter reading

5. Wind speed

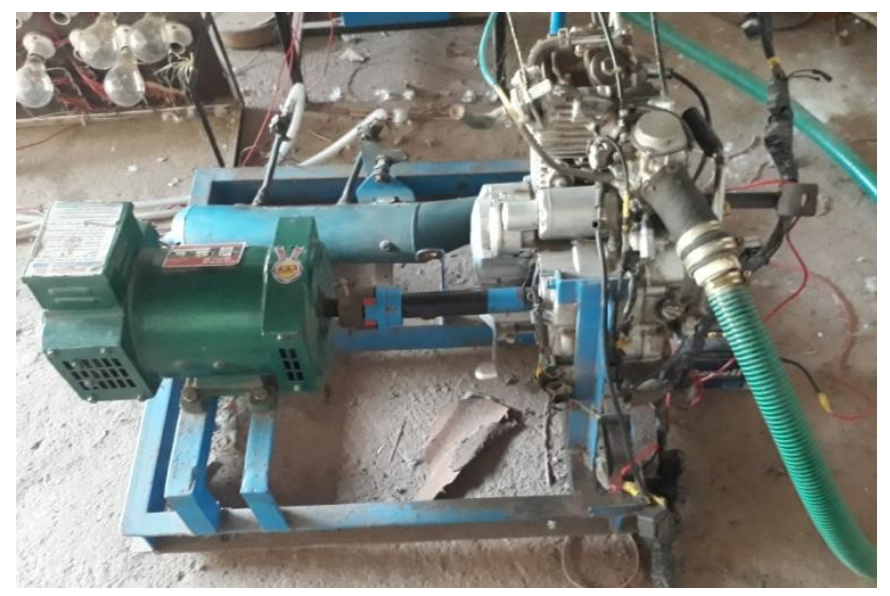

Fig.1: IC ENGINE TEST RIG

With the aide of above parameters, performance factors like, $\eta_{B r . t h}$, B.S.F.C etc., are evaluated. The above experiment is repeatedly carried out for three various configurations of cylinder blocks i.e., 1. Actual cylinder block 2.Cylinder block with fins of triangular profile. 3. Engine block with perforated fins of triangular profile.

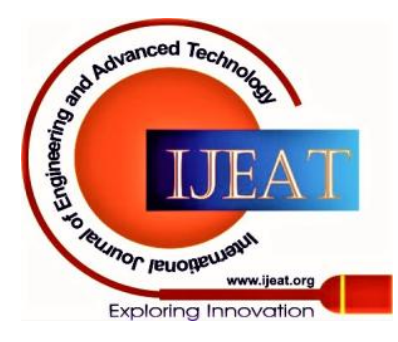




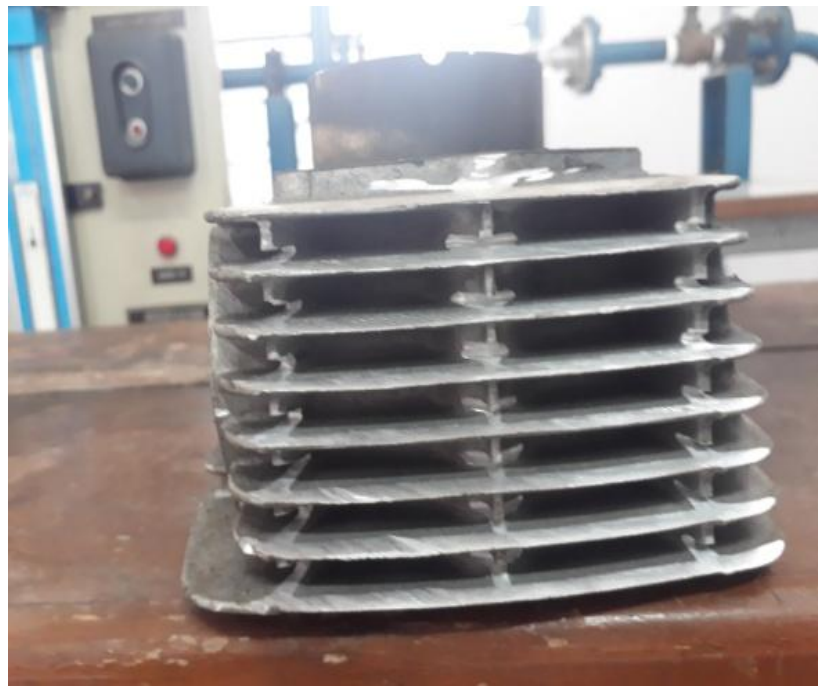

Fig. 2: IC Engine Cylinder Block

\section{RESULTS AND DISCUSSIONS}

For the same wind speed, pitch, number of fins., brake thermal efficiency, brake power of altered engine with engine block of perforated fins of triangular profile are more than the original engine (Engine block of rectangular profile fins).

For the same wind speed, number of fins., B.S.F.C. of altered I.C. Engine with engine block of perforated fins of triangular profile are lower than the original engine (Engine block of rectangular profile fins).

Performance factors like Brake Thermal Efficiency (BTF), Brake Power (BP) and Brake Specific Fuel Consumption (B.S.F.C.) of modified engine with engine block of fins of triangular profile are lies between other two configurations.

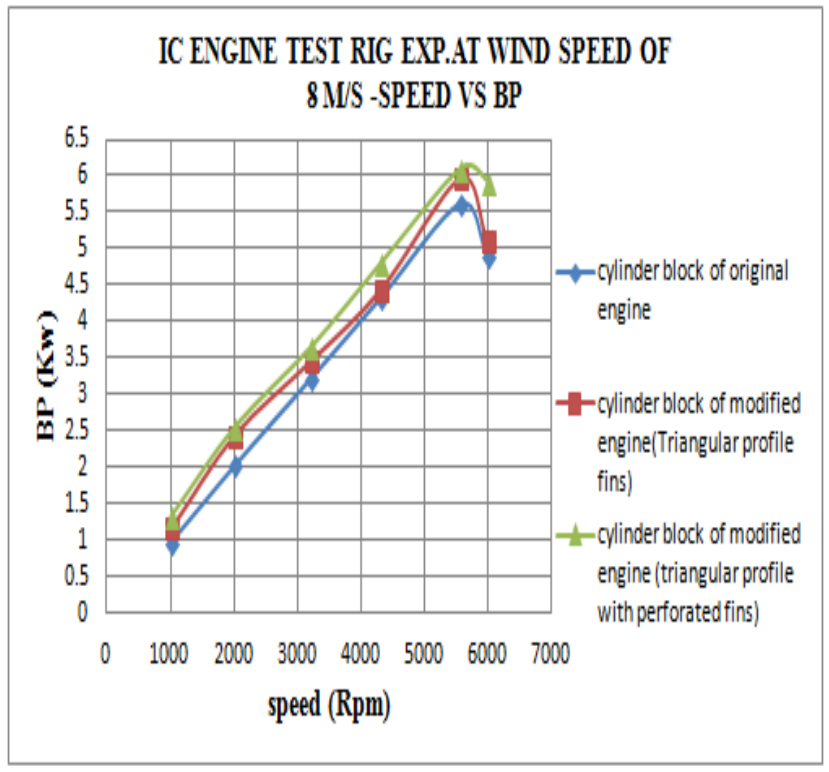

Graph 1: Speed - Bp at (wind speed $8 \mathrm{~m} / \mathrm{s}$ )

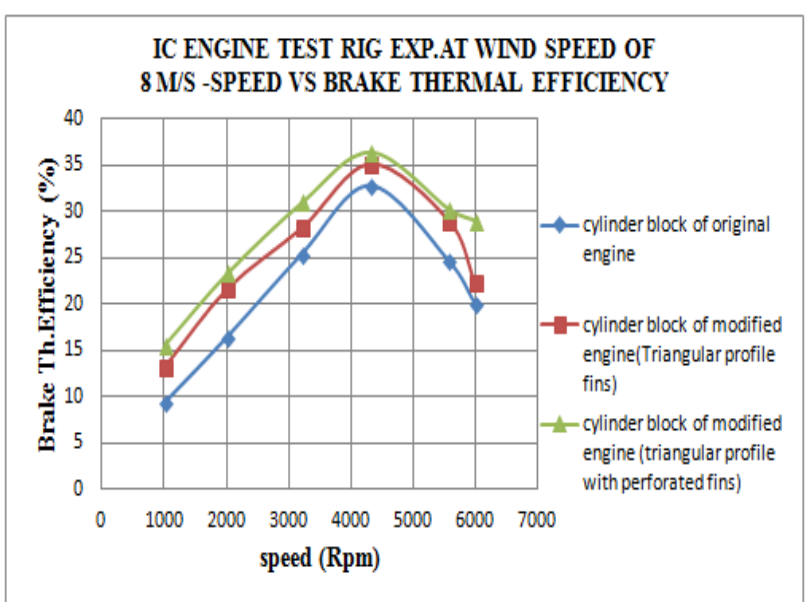

Graph 2: Speed $-\eta_{B r . t h .}$ (wind speed $8 \mathrm{~m} / \mathbf{s}$ )

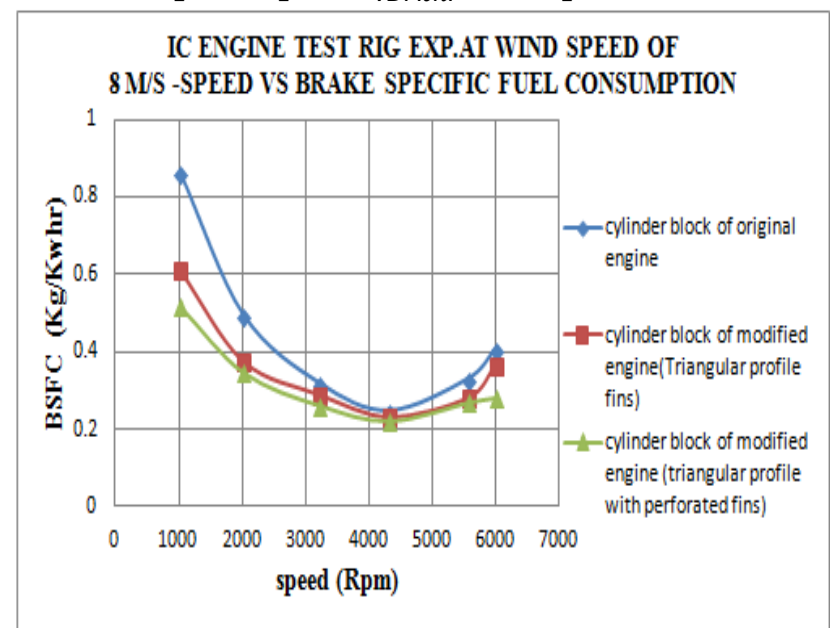

Graph 3: Speed -B.S.F.C.(wind speed $8 \mathrm{~m} / \mathrm{s}$ )

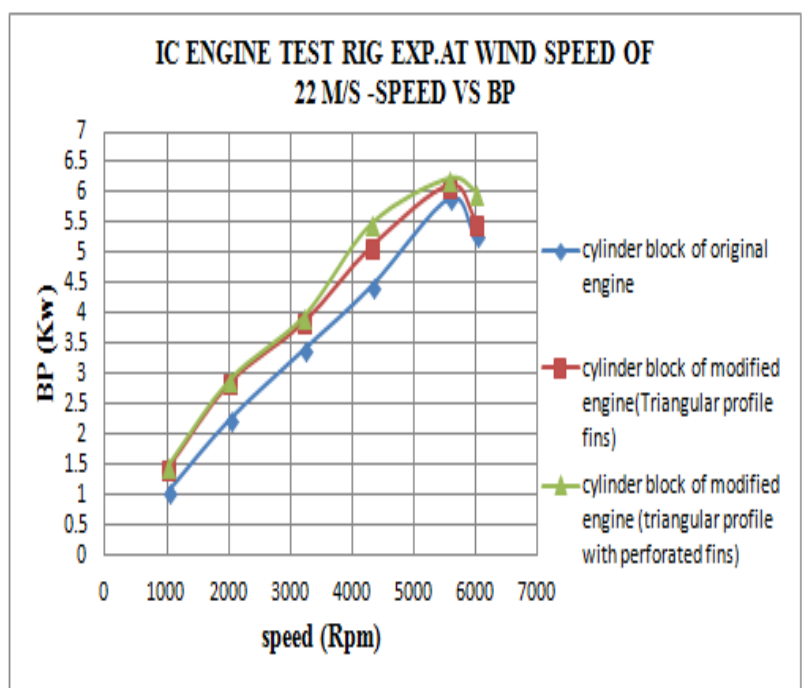

Graph 4: Speed - Bp (wind speed 22 m/s)

Published By:

Blue Eyes Intelligence Engineering and Sciences Publication

(C) Copyright: All rights reserved.

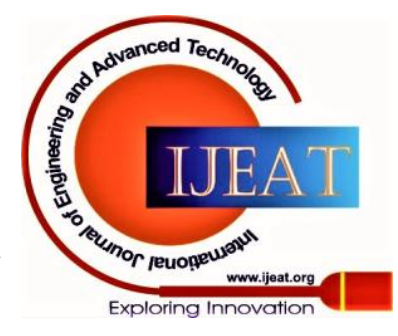




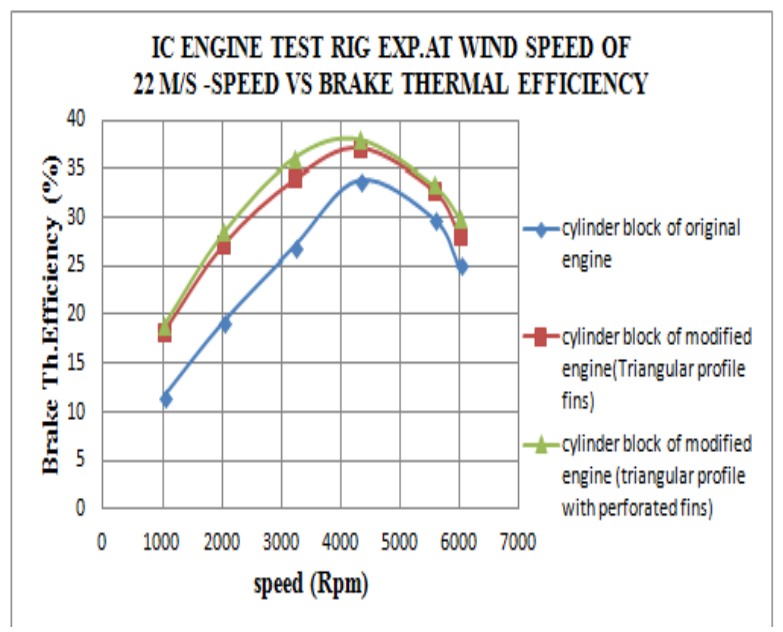

Graph 5: Speed $-\eta_{B r . t h}$ (wind speed $22 \mathrm{~m} / \mathrm{s}$ )

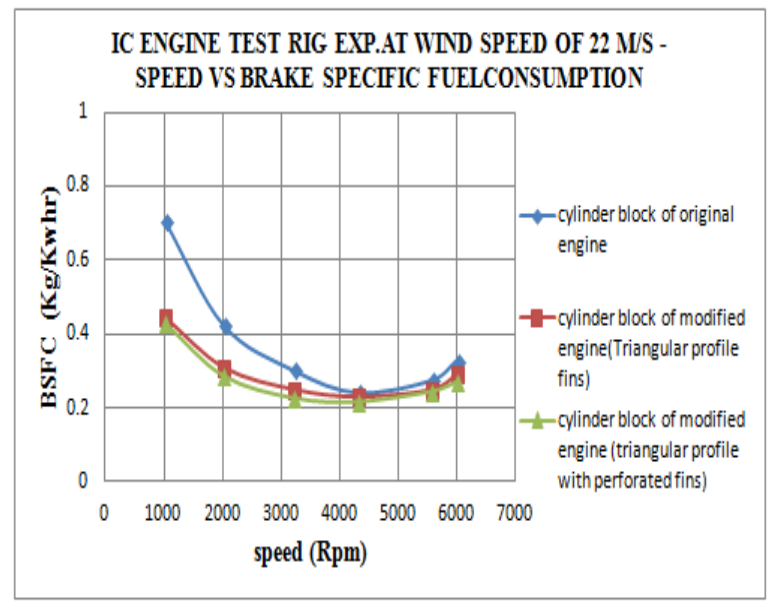

Graph 6: Speed vs B.S.F.C. (wind speed $22 \mathrm{~m} / \mathrm{s}$ )

When all three configurations subjected tohigh wind speeds, optimum results i.e. B.P, $\eta_{B r . t h}$, B.S.F.C., obtained. During high wind speeds, the performance of altered I.C. Engine with engine block of perforated fins of triangular profile is higher compared to other two configurations.

\section{CONCLUSIONS}

Experimentation is carried out with I.C. Engine test rig by using actual and modified cylinder blocks.

The following conclusions are made:

1. The performance of the modified engine with cylinder block of perforated fins of triangular profile is maximum, due to augmented heat transfer.

2. When perforated fins are used, the load of the fins array on the engine becomes less, which increases the fuel efficiency.

3. Due to increase in rate of cooling and engine operation at controlled temperatures, the breathing ability of the engine increases, therefore volumetric efficiency of the engine also increases. Further, because of complete combustion, apart from increase in fuel economy, pollution levels also comes down.

\section{REFERENCES}

1. Deepak Gupta, Wankhade S.R "Design and analysis of cooling fins" (IJMER), ISSN (Print): 2321-5747, Vol 3, Issue 2, 2015, PP:1-4

2. Mohsen Torabi, Hessameddin Yaghoobi, Mohammad Reza Kiani "Thermal Analysis of the convective - radiative fin with a step change in thickness and temperature dependent thermal conductivity" Journal of theoretical and applied mechanics 51, 3, PP: 593-602, warsaw 2013

3. N. Phani Raja Rao, T. Vishnu Vardhan, "Thermal Analysis of Engine Cylinder Fins by Varying its Geometry and Material", (IJERT), ISSN:2278-0181, Vol. 2, Issue 8, August 2013, PP: 404-412.

4. R. Arularasan, P. Hemanandhan, T.Thamizhselvan, B. ArunKumar, S.Senthilnathan, S, Prathap, "Modeling and Simulation of Engine Cylinder Fins by using FEA", (IJRASET), ISSN: 2321-9653, Vol 2, Issue IV, April 2014, PP:403-408

5. P. Sai Chailtanya, B. Suneela Rani, K. Vijaya Kumar, "ThermalAnalysis of Engine Cylinder Fin by Varing its Geometry and Material" (IOSRJMCE), e-ISSN: 2278-1684, p-ISSN: 2320-334X, Volume 11, Issue 6 ver. I (Nov-Dec 2014) PP: 37-44.

6. Esmail M.A Mokheimer, "Performance of Annular Fins withDifferent Profiles Subject to Variable Heat Transfer Coefficient", International Journal of Heat and Mass Transfer (2002) 3631-3642

7. Cihat Arslanturk, "Analysis of Thermal Performance of AnnularFins with Variable Thermal Conductivity by Homotopy AnalysisMethod", Int. Journal of Thermal Science and Technology,ISSN:1300-3615, (C) 2010, TIBTD Printed in Turkey.

\section{AUTHOR'S PROFILE}

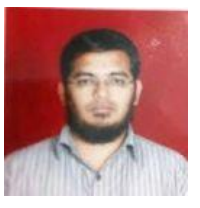

Mr. Mohd Abdul Samad, presently working as Assistant Professor, Mechanical Engineering Department, MJCET, Hyderabad. Total teaching Experience is 18 years. Area of interest is Heat Transfer and IC Engines.

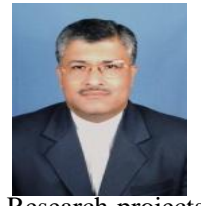

Dr. Syed Nawazish Mehdi, presently working as a Professor and R\&D Director, In Department of Mechanical Engineering, Lords Institute of Engineering and Technology. Produced $8 \mathrm{Ph} . \mathrm{Ds}$ and guiding $17 \mathrm{PhDs}$. Published 75 technical papers in various international and national journals. Total teaching experience is 35 years. Research projects funded by Central and State Government is 5 completed as principal investigator. Area of interest is IC Engines, Renewable energy sources and Thermal Engineering.

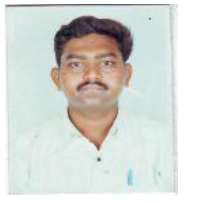

Dr. Syed Khader Basha, presently working as Assistant Professor, Mechanical Engineering Department, MJCET, Hyderabad. Total teaching Experience is 20 years. Area of interest is Heat Transfer and IC Engines.
Published By:

Blue Eyes Intelligence Engineering and Sciences Publication

8 (c) Copyright: All rights reserved.

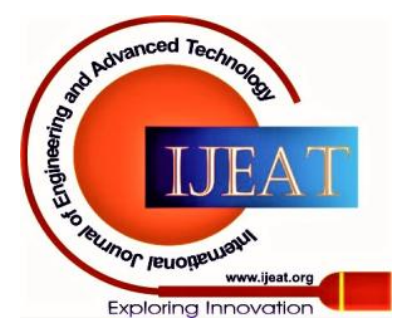

